\title{
Efficacy of Intra-Articular Injection of Thrombin-Based Hemostatic Agent in the Control of Bleeding after Primary Total Knee Arthroplasty
}

\author{
Ki-Cheor Bae, MD, Chul-Hyun Cho, MD, Kyung-Jae Lee, MD, Eun-Seok Son, MD, Si-Wook Lee, MD, \\ Suk-Joong Lee, MD, and Kyung Hwan Lim, MD \\ Department of Orthopedic Surgery, Keimyung University Dongsan Medical Center, Daegu, Korea
}

\begin{abstract}
Purpose: To evaluate the hemostatic effect of intraarticular injection of a thrombin-based hemostatic agent in total knee arthroplasty (TKA). Materials and Methods: We performed a prospective randomized controlled trial on the use of a thrombin-based hemostatic agent in patients undergoing unilateral TKA. A total of 100 TKA patients were enrolled, with 50 patients randomized into the study group and the other 50 patients into the controlled group. Drain output, hemoglobin level, total red blood cell loss for 24 hours after surgery, transfusion rates, and complications were assessed.

Results: Postoperative drain output was $525 \mathrm{~mL}$ in the study group and $667 \mathrm{~mL}$ in the control group (p=0.01). Nine patients in the study group and eighteen in the control group received blood transfusion $(\mathrm{p}=0.043)$. But, there was no significant difference between two groups in terms of hemoglobin level change and total red blood cell loss ( $\mathrm{p}>0.05)$.

Conclusions: The thrombin-based hemostatic agent demonstrated efficacy in reducing drain output and blood transfusion rates. Thus, we believe the use of a thrombin-based hemostatic agent should be considered as an option in orthopedic surgery that involves massive bleeding.
\end{abstract}

Keywords: Knee, Osteoarthritis, Arthroplasty, Bleeding, Hemostatic agent

\section{Introduction}

Total knee arthroplasty (TKA) is the gold standard treatment for advanced osteoarthritis refractory to nonoperative management; however, the procedure involves approximately $2,000 \mathrm{~mL}$ of perioperative blood loss, which often results in complications and necessitates transfusion ${ }^{1-3)}$. Allogeneic blood transfusion carries the risk of viral infection, fever, and immunosuppression.

Received November 29, 2013; Revised (1st) January 17, 2014; (2nd) April 13, 2014; (3rd) July 1, 2014; (4th) September 1, 2014; (5th) September 13, 2014; Accepted September 16, 2014

Correspondence to: Ki-Cheor Bae, MD

Department of Orthopedic Surgery, Keimyung University Dongsan

Medical Center, 56 Dalseong-ro, Jung-gu, Daegu 700-712, Korea

Tel: +82-53-250-7729, Fax: +82-53-250-7205

E-mail: bkc@dsmc.or.kr

This is an Open Access article distributed under the terms of the Creative Commons Attribution Non-Commercial License (http://creativecommons.org/licenses/by-nc/3.0/) which permits unrestricted non-commercial use, distribution, and reproduction in any medium, provided the original work is properly cited.
Thus, research has been pursued for minimal blood loss with use of various hemostatic agents, such as fibrin and tranexamic acid $^{4-10)}$. Floseal (Baxter, Deerfield, IL, USA), a thrombin-based hemostatic agent, is composed of two independent hemostasispromoting agents, bovine-derived gelatin matrix component and human-derived thrombin. A high concentration of human thrombin accelerates blood clotting by converting fibrogen to fibrin, and gelatin matrix swells upon contact with moisture, producing a tamponade effect to control blood loss. It has been employed in a wide range of medical fields including orthopedic surgery, neurosurgery, otolaryngology, and obstetrics and gynecology; thus, it is expected to be useful in TKA that involves substantial blood loss ${ }^{11)}$.

In this study, we investigated the impact of intraarticular injection of the thrombin-based hemostatic agent on blood loss following TKA.

\section{Materials and Methods}

This study was conducted under Institutional Review Board 
Table 1. Demographic Data

\begin{tabular}{lccc}
\hline \multicolumn{1}{c}{ Variable } & Group I & Group II & p-value \\
\hline No. of patients & 50 & 50 & \\
Age $(\mathrm{yr})$ & $68.8 \pm 7.70$ & $69.0 \pm 6.66$ & 0.895 \\
Sex (male:female) & $4: 46$ & $8: 42$ & 0.211 \\
Body mass index $\left(\mathrm{kg} / \mathrm{m}^{2}\right)$ & $26.41 \pm 4.30$ & $24.81 \pm 3.07$ & 0.063 \\
CR:PS type & $22: 28$ & $26: 24$ & \\
\hline
\end{tabular}

Values are presented as mean \pm standard deviation or number.

CR: cruciate retraining, PS: posterior cruciate substituting.

approval. A total of 100 patients who underwent unilateral TKA under the diagnosis of degenerative osteoarthritis at our institution between December 2011 and June 2013 were included in this study. The patients were randomly assigned to either the experimental group with use of the thrombin-based hemostatic agent (group I, $\mathrm{n}=50$ ) or the control group without the agent (group II, $\mathrm{n}=50$ ) (Table 1). The implants of choice were either PFC Sigma (DePuy Orthopaedics Inc., Warsaw, IN, USA) or Scorpio NRG (Stryker, Allendale, NJ, USA). Ten patients in each group had been on anticoagulant therapy due to cardiovascular diseases or cerebrovascular diseases, which was discontinued at least 5 days prior to surgery and was re-instituted on the 5th postoperative day if there was no sign of blood loss. Patients who could not tolerate discontinuation of the anticoagulant therapy, underwent bilateral TKA, or had bleeding disorders were excluded from the study.

With the patient placed in the supine position, the surgery was performed through a midline incision. A tourniquet was applied prior to skin incision at $350 \mathrm{mmHg}$ and released upon completion of skin closure. Femoral resection was done using an intramedullary alignment guide and tibial resection was carried out using an extramedullary alignment guide. Bone cement was used for fixation in the femur and tibia. The patella was resurfaced in 2 knees in group I and in 5 knees in group II after intraoperative confirmation of advanced arthritis in the patellofemoral joint. In group I, after femoral and tibial component placement, $5 \mathrm{~mL}$ thrombin-based hemostatic agent was applied to the medial, lateral, and posterior compartments and the suprapatellar bursa before liner insertion (Fig. 1). A drainage tube was placed in all patients and drainage was started 1 hour after surgery. In all patients, quadriceps femoris strengthening exercises and active joint exercises were initiated from the 1st postoperative day. Ambulation was encouraged when quadriceps femoris strengthening exercises could be accomplished without difficulty.

Hemoglobin level was measured daily from the preoperative day to the 3 rd postoperative day. The drain output was measured on

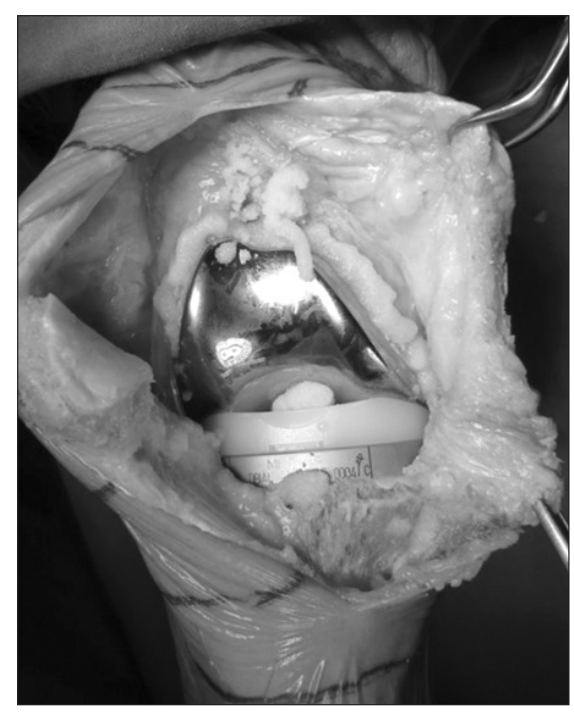

Fig. 1. Application of a thrombin-based hemostatic agent after implant insertion.

the day of surgery and 1st postoperative day, and the tube was removed on the 2 nd postoperative day. The total red blood cell loss within 24 postoperative hours was calculated using preoperative circulating blood volume and postoperative hematocrit change taking into account that hemodynamic changes are caused by intraoperative/postoperative blood loss. The following equation suggested by Gross $^{12)}$ in 1983 was used for the calculation of total red blood cell loss: total red blood cell loss=preoperative circulating blood volumex ([preoperative hematocrit-postoperative hematocrit]/mean hematocrit) ${ }^{13)}$.

The preoperative circulating blood volume was calculated using the method of Nadler et al. ${ }^{14)}$ as follows: preoperative circulating blood volume $=\mathrm{k} 1 \times$ height $(\mathrm{m})+\mathrm{k} 2 \times$ weight $(\mathrm{kg})+\mathrm{k} 3$ ( $\mathrm{K}$ is a constant, $\mathrm{k} 1=0.3669, \mathrm{k} 2=0.03219, \mathrm{k} 3=0.6041$ for male and 0.3561 , $0.03308,0.1833$ for female, respectively).

Packed red blood cell transfusion was performed if a hemoglobin level was below $8.5 \mathrm{~g} / \mathrm{dL}$ for 3 postoperative days. The pretransfusion hemoglobin values were included in the statistical analysis, but post-transfusion levels were excluded. The intraoperative blood loss was not included in the statistical analysis due to the difficulty of objective measurement caused by the tourniquet use. At 1 week after surgery, vascular sonography was performed to identify the presence of deep venous thrombosis, and the surgical site was examined to assess the occurrence of wound infection or bleeding.

Statistical analysis was done using SPSS ver. 18.0 (SPSS Inc., Chicago, IL, USA). Patient characteristics, such as gender and surgical site, were compared using chi-square test. Pre- and postoperative changes were compared using t-test. The level of 
significance for all tests was set at $\mathrm{p}<0.05$.

\section{Results}

\section{Patient Characteristics}

In group I, there were 4 males and 46 females, and their mean age was 68.8 years. In group II, there were 8 males and $42 \mathrm{fe}$ males, and their mean age was 69.0 years. There was no statistically significant intergroup difference with regard to the age, gender, implant type, and body mass index ( $p>0.05)$.

\section{Postoperative Blood Loss (Drain Output)}

The mean postoperative drain output was $525 \mathrm{~mL}(393 \mathrm{~mL}$ on the day of surgery $+132 \mathrm{~mL}$ on the 1 st postoperative day) in group I and $667 \mathrm{~mL}(513 \mathrm{~mL}$ on the day of surgery+154 mL on the 1st postoperative day) in group II. Thus, the postoperative blood loss volume was $22 \%$ less in group I than group II, showing statistical significance $(\mathrm{p}=0.01)$ (Table 2$)$.

\section{Hemoglobin Level Change}

Pre-transfusion hemoglobin levels were included in statistical analysis and the post-transfusion levels were not analyzed. In group $\mathrm{I}$, the mean change in hemoglobin level between the preoperative period and the $3 \mathrm{rd}$ postoperative day was $2.88 \mathrm{~g} /$ $\mathrm{dL}$ : the value was $12.13 \mathrm{~g} / \mathrm{dL}$ preoperatively, $10.18 \mathrm{~g} / \mathrm{dL}$ on the $1 \mathrm{st}$ postoperative day, $9.45 \mathrm{~g} / \mathrm{dL}$ on the 2 nd postoperative day, and $9.25 \mathrm{~g} / \mathrm{dL}$ on the third postoperative day. In group II, the mean hemoglobin level change was $3.00 \mathrm{~g} / \mathrm{dL}$ during the same period: the value was $12.00 \mathrm{~g} / \mathrm{dL}$ preoperatively, $9.95 \mathrm{~g} / \mathrm{dL}$ on the 1 st postoperative day, $9.17 \mathrm{~g} / \mathrm{dL}$ on the 2 nd postoperative day, and $9.00 \mathrm{~g} / \mathrm{dL}$ on the $3 \mathrm{rd}$ postoperative day. Although $0.12 \mathrm{~g} / \mathrm{dL}$ less change was noted in group I, the difference was not statistically significant between the groups ( $\mathrm{p}>0.05$ ) (Table 3 ).

\section{Allogeneic Blood Transfusion}

In group I, allogeneic blood transfusion was performed in a total of 9 patients ( 3 on the 1st postoperative day, 4 on the 2 nd postoperative day, and 2 on the 3 rd postoperative day). In group

Table 2. Postoperative Blood Loss

\begin{tabular}{lccc}
\hline & Group I $(\mathrm{mL})$ & Group II $(\mathrm{mL})$ & p-value \\
\hline Operative day & $393 \pm 191$ & $513 \pm 279$ & 0.015 \\
POD 1 & $132 \pm 64$ & $154 \pm 101$ & 0.200 \\
Total & $525 \pm 228$ & $667 \pm 303$ & 0.010 \\
\hline
\end{tabular}

Values are presented as mean \pm standard deviation.

POD: postoperative day.
II, a total of 18 patients received transfusion (5 on the 1st postoperative day, 10 on the 2 nd postoperative day, 3 and on the $3 \mathrm{rd}$ postoperative day). The blood transfusion rate was significantly different between the groups $(\mathrm{p}=0.043)$ (Table 4).

\section{Total Red Blood Cell Loss within 24 Hours after Surgery}

The total red blood cell loss within the first 24 hours after surgery was measured as an average of $593 \mathrm{~mL}$ (range, 13 to 1,478 $\mathrm{mL}$ ) in group I and $609 \mathrm{~mL}$ (range, 101 to 1,494 mL) in group II. The $16 \mathrm{~mL}$ of difference between the groups did not reach statistical significance $(\mathrm{p}=0.655)$.

\section{Complications}

Vascular sonography performed 1 week after surgery revealed the presence of deep venous thrombosis in 7 patients in group I (femoral vein thrombosis in 2, popliteal vein thrombosis in 2, and peroneal vein thrombosis in 3) and in 9 patients in group II (popliteal vein thrombosis in 2 and peroneal vein thrombosis in 7), showing no statistically significant difference between the groups ( $p>0.05$ ). All of the patients diagnosed with deep venous thrombosis received anticoagulant treatment in consultation with vascular surgery. Other complications, such as local/deep infection and wound bleeding were not observed during the followup.

\section{Discussion}

Allogeneic blood transfusion is often necessary in surgery that involves substantial blood loss. Unfortunately, it has been associated with some adverse outcomes: disease transmission, such as AIDS and hepatitis, alloantibody responses, and graft-versus-host reactions ${ }^{1,3)}$. Thus, efforts have been made to reduce intraopera-

Table 3. Initial \& Postoperative Hemoglobin Level

\begin{tabular}{lccc}
\hline & Group I $(\mathrm{g} / \mathrm{dL})$ & Group II $(\mathrm{g} / \mathrm{dL})$ & p-value \\
\hline Preoperative & $12.13 \pm 1.40$ & $12.00 \pm 1.34$ & 0.651 \\
POD 1 & $10.18 \pm 1.35$ & $9.95 \pm 1.35$ & 0.455 \\
POD 2 & $9.45 \pm 1.03$ & $9.17 \pm 1.19$ & 0.221 \\
POD 3 & $9.25 \pm 0.96$ & $9.00 \pm 1.12$ & 0.345 \\
\hline
\end{tabular}

Values are presented as mean \pm standard deviation. POD: postoperative day.

Table 4. Number of Blood Transfusion

\begin{tabular}{cccc}
\hline & Group I & Group II & p-value \\
\hline Total & 9 & 18 & 0.043 \\
\hline
\end{tabular}


tive blood loss using hypotensive anesthesia and administration of hemostatic agents ${ }^{1,3-5,15}$, and the latter has been the focus of recent research.

Considering that hemodynamic changes after TKA result from coagulation and fibrinolysis, studies have suggested that intravenous administration of dextran, tranexamic acid, amnocaproic acid, and aprotinin would be effective in reducing perioperative blood loss ${ }^{15-19)}$.

Besides intravenous injection, direct application of hemostatic agents on the operative site has been addressed in many studies. Marmor et al. ${ }^{10)}$ coated the operative site with fibrinogen concentrate to induce fibrin clot formation, which resulted in $16 \%$ reduction in the total blood loss and $76 \%$ reduction in the intraoperative blood loss. In the study, they suggested that fibrinogen concentrates would be more beneficial for reducing inapparent blood loss than postoperative blood loss. Song and Park ${ }^{20)}$ compared the hemoglobin level, hematocrit value, and the frequency of autotransfusion between 40 TKA patients with fibrin glue that contains fibrinogen and 31 TKA patients without fibrin glue and reported that fibrin glue was remarkably effective for bleeding control.

In our study, we used Floseal, a hemostatic agent composed of bovine collagen granules and human thrombin, which has an increased presence in orthopedic surgery, neurosurgery, thoracic surgery, and obstetrics and gynecology. Kim et al. ${ }^{21)}$ investigated the efficacy of the thrombin-based hemostatic matrix after unilateral TKA. The 24-hour drain output was not significantly different between the Floseal group $(n=97)$ and the control group $(\mathrm{n}=97 ; 711 \mathrm{~mL}$ vs. $701 \mathrm{~mL})$. The knee range of motion and visual analog scale score were not significantly different between the groups. However, a statistically significant intergroup difference was noted in the hemoglobin level change: notably less changes were observed between the preoperative values and the first and second postoperative day values in the Floseal group ${ }^{21)}$. In our study, the total drain output and transfusion rates were significantly low in the Floseal group, whereas the hemoglobin level change and 24-hour red blood cell loss showed no significant difference between the groups. Kim et al. ${ }^{22)}$ reported that there was a significant relation between tourniquet pressure and subcutaneous bleeding after TKA: the amount of subcutaneous bleeding after TKA significantly increased when the surgery was performed under a tourniquet pressure of $320 \mathrm{mmHg}$ than 250 $\mathrm{mmHg}$. In our study, TKA was performed under a relatively high tourniquet pressure of $350 \mathrm{mmHg}$, thus we could have underestimated insensible blood loss caused by tourniquet application. In addition, blood transfusion was performed in patients with $<8.5$
g/dL hemoglobin level without taking consideration into symptoms, blood pressure, and heart rate. Other limitations of this study include that 1 ) the hemoglobin level changes were relatively insignificant by excluding from the analysis the vales obtained from the 4th postoperative day and after transfusion, 2) and the potential risk of complications, such as infection, could not be assessed due to the lack of long-term follow-up.

\section{Conclusions}

The use of a thrombin-based hemostatic agent resulted in $22 \%$ decrease in drain output and significant reduction in the need for blood transfusion after TKA. The hemoglobin level change and 24-hour red blood cell loss were more notable in the hemostatic agent group $(n=50)$ than in the control group $(n=50)$, but the difference was not statistically significant. Therefore, we believe that thrombin-based hemostatic agents would be effective for reducing blood loss in orthopedic surgery, such as TKA that involves the risk of massive blood loss.

\section{Conflict of Interest}

No potential conflict of interest relevant to this article was reported.

\section{References}

1. Kim JM, Kim YS, Kim SS, Kong JT, Kim KW. Blood loss after total knee replacement. J Korean Knee Soc. 1991;3:152-6.

2. Bae DK, Nam GU, Lee HK, Kim YH. Reinefusion of shed blood through the orthop-evac after total knee replacemnet. J Korean Knee Soc. 1994;6:88-93.

3. Song EK, Kim JU. Retrieval and autotransfusion of whole blood after total knee arthroplasty. J Korean Knee Soc. 1996; 8:156-61.

4. Berman AT, Geissele AE, Bosacco SJ. Blood loss with total knee arthroplasty. Clin Orthop Relat Res. 1988;(234):137-8.

5. Cushner FD, Friedman RJ. Blood loss in total knee arthroplasty. Clin Orthop Relat Res. 1991;(269):98-101.

6. de Haan J, Boonstra PW, Monnink SH, Ebels T, van Oeveren W. Retransfusion of suctioned blood during cardiopulmonary bypass impairs hemostasis. Ann Thorac Surg. 1995;59: 901-7.

7. Faris PM, Ritter MA, Keating EM, Valeri CR. Unwashed filtered shed blood collected after knee and hip arthroplasties: a source of autologous red blood cells. J Bone Joint Surg Am. 
1991;73:1169-78.

8. Semkiw LB, Schurman DJ, Goodman SB, Woolson ST. Postoperative blood salvage using the Cell Saver after total joint arthroplasty. J Bone Joint Surg Am. 1989;71:823-7.

9. Healy WL, Pfeifer BA, Kurtz SR, Johnson C, Johnson W, Johnston R, Sanders D, Karpman R, Hallack GN, Valeri CR. Evaluation of autologous shed blood for autotransfusion after orthopaedic surgery. Clin Orthop Relat Res. 1994;(299): 53-9.

10. Marmor L, Avoy DR, McCabe A. Effect of fibrinogen concentrates on blood loss in total knee arthroplasty. Clin Orthop Relat Res. 1991;(273):136-8.

11. Solimeno LP, Casadei C, Pasta G, Perfetto O. Blood-sparing knee surgery in patients with haemophilia: use of a novel haemostatic matrix. Euro Musculoskelet Rev. 2008;3:33-6.

12. Gross JB. Estimating allowable blood loss: corrected for dilution. Anesthesiology. 1983;58:277-80.

13. Ward CF, Meathe EA, Benumof JL, Trousdale F. A computer nomogram for blood loss replacement. Anesthesiology. 1980;53:S126.

14. Nadler SB, Hidalgo JH, Bloch T. Prediction of blood volume in normal human adults. Surgery. 1962;51:224-32.

15. Carlin G, Karlstrom G, Modig J, Saldeen T. Effect of dextran on fibrinolysis inhibition activity in the blood after major surgery. Acta Anaesthesiol Scand. 1980;24:375-8.

16. Choi YJ, Hwang JK, Ahn HS, Bae EJ, Kim CH, Kim E. The effect of aprotinin for reducing blood loss and amount of transfusion in total knee arthroplasty. J Korean Knee Soc. 2005;17:241-5.

17. Sepah YJ, Umer M, Ahmad T, Nasim F, Chaudhry MU, Umar M. Use of tranexamic acid is a cost effective method in preventing blood loss during and after total knee replacement. J Orthop Surg Res. 2011;6:22.

18. Camarasa MA, Olle G, Serra-Prat M, Martín A, Sanchez M, Ricos P, Perez A, Opisso L. Efficacy of aminocaproic, tranexamic acids in the control of bleeding during total knee replacement: a randomized clinical trial. Br J Anaesth. 2006; 96:576-82.

19. Horrow J, Strong MD, Van Riper DF. Tranexamic acid after bypass: too late to help? J Thorac Cardiovasc Surg. 1994;107: 1375-7.

20. Song EK, Park YB. Fibrin glue for bleeding after total knee arthroplasty. J Korean Knee Soc. 1998;10:148-53.

21. Kim HJ, Fraser MR, Kahn B, Lyman S, Figgie MP. The efficacy of a thrombin-based hemostatic agent in unilateral total knee arthroplasty: a randomized controlled trial. J Bone Joint Surg Am. 2012;94:1160-5.

22. Kim JH, Lee S, Kim KT, Ko DO, Yang JH, Lee JS, Kim DG. Relationship between the tourniquet pressure and the amount of subcutaneous bleeding after total knee replacement. J Korean Knee Soc. 2011;23:19-26. 